\title{
Knowledge of Signs, Symptoms, Risk Factors, and Complications of Obstructive Sleep Apnea among Dental
}

\section{Interns}

\author{
Reem A Alansari ${ }^{1}$, Abdullah S Kaki ${ }^{2}$
}

\begin{abstract}
Dentists are uniquely positioned to identify patients at risk of obstructive sleep apnea (OSA) and its complications. However, previous reports have shown that the average general dentist possesses insufficient knowledge about the clinical manifestations and complications of OSA. Aim: The purpose of this study was to examine Saudi dental interns' knowledge related to the clinical manifestations and impact of OSA. Materials and methods: This was a cross-sectional study using a self-administered questionnaire to assess the interns' knowledge related to the symptoms, signs, diagnosis, risk factors, and complications of OSA in adults and children.

Results: The average of the proportions of factually correct participant responses of the questionnaire categories was $47 \%$. Participants did best in the category of questions related to predisposing factors ( $50 \%$ of questions were answered correctly), but less than $50 \%$ of questions were answered correctly in other OSA-related areas. Most participants scored $49 \%$ or lower in this questionnaire.

Conclusion: Saudi dental interns had poor knowledge related to OSA. This may relate to the insufficiency of teaching sleep-related topics in dental curricula, among other reasons.

Clinical significance: Given the potential impact of OSA on cardiovascular health, metabolic syndrome, and other public health problems, it is important to remedy this knowledge gap and empower future physicians with the knowledge required to participate in detecting OSA patients and referring them for evaluation.

Keywords: Awareness, Dental interns, Obstructive sleep apnea, Saudi.

The Journal of Contemporary Dental Practice (2020): 10.5005/jp-journals-10024-2801
\end{abstract}

\section{INTRODUCTION}

Obstructive sleep apnea (OSA) is a medical condition characterized by partial or complete collapse of the upper respiratory airway during sleep, leading to repetitive bouts of apneas, hypopneas, hypoxia, hypercapnia, and sleep disruption. Obstructive sleep apnea carries the potential of serious cardiovascular and neuropsychiatric morbidity. It worsens arterial hypertension, increases the risk of ischemic vascular events, cognitive impairment, and depression. In children, it impairs school performance and may lead to behavioral problems. Obstructive sleep apnea symptoms may include snoring, repetitive arousals from sleep with breathing difficulties, excessive daytime sleepiness, headaches, and other symptoms. Recognition and treatment of obstructive sleep apnea (OSA) is crucial for reducing its associated symptoms and chronic complications. ${ }^{1}$ Unfortunately, OSA remains one of the most underdiagnosed and untreated chronic conditions despite the availability of effective treatments such as continuous positive airway pressure. Delay in the diagnosis and treatment has been linked to morbidity and mortality mainly through progression of cardiovascular disease. ${ }^{2}$ Obstructive sleep apnea is a common condition worldwide including Saudi Arabia, where the prevalence is reported to be around $12 \%$ in men and $5 \%$ in women. ${ }^{3}$

The role of dentists in the screening and management of OSA has been considered and described in the literature. ${ }^{4}$ Dentists are uniquely positioned to screen, identify adults and children at risk of OSA, and refer them to sleep physicians. A high number of patients with OSA visit dentists frequently for various reasons. ${ }^{5}$ Dentists routinely evaluate the upper airway during dental examinations \begin{tabular}{l}
\hline 'Department of Orthodontics, Faculty of Dentistry, King Abdulaziz \\
University, Jeddah, Kingdom of Saudi Arabia \\
2Primary Dental Care Department, Taif Dental Center, Ministry of \\
Health, Taif, Kingdom of Saudi Arabia \\
Corresponding Author: Reem A Alansari, Department of Orthodontics, \\
Faculty of Dentistry, King Abdulaziz University, Jeddah, Kingdom of \\
Saudi Arabia, e-mail: ralansari@kau.edu.sa \\
How to cite this article: Alansari RA, Kaki AS. Knowledge of Signs, \\
Symptoms, Risk Factors, and Complications of Obstructive Sleep \\
Apnea among Dental Interns. J Contemp Dent Pract 2020;21(5): \\
$558-561$. \\
Source of support: Nil \\
Conflict of interest: None \\
\hline \hline
\end{tabular}

and may be able to identify those with small airways. Furthermore, dentists can participate in the care pathway of patients with OSA when oral appliance therapy (OAT) may be useful to treat OSA. These roles of dentists in the care of patients with OSA have been described in practice guidelines issued by the American Academy of Sleep Medicine and the American Academy of Dental Sleep Medicine. ${ }^{6}$ Unfortunately, studies have shown suboptimal knowledge and awareness of general dentists and dental trainees with regard to the nature of OSA and their potential roles in the screening and management of these patients. For example, it was shown that less than $50 \%$ of dentists is able of identify common OSA signs and symptoms. ${ }^{5}$ In another study, nearly $60 \%$ of a sample of general dentists could not identify OSA's signs and symptoms, and a majority of them reported they do not have sufficient knowledge 
about the condition. ${ }^{7}$ A recent study showed that $65 \%$ of a sample of final year dental students in a Saudi dental school was not knowledgeable about how to diagnose OSA. ${ }^{8}$ It appears, therefore, that there may be a knowledge gap that would allow dentists to participate effectively in the screening process for OSA. The aim of this study was to examine Saudi dental interns' knowledge of OSA signs, symptoms, risk factors, and complications.

\section{Materials and Methods}

The Institutional Review Board of King Abdulaziz University Faculty of Dentistry (KAUFD) approved this study (project \# 014-16). This was a cross-sectional study of a convenient sample of dental interns. One hundred and fifty-eight dental interns from governmental and private dental schools were recruited for the study. Both dental schools adopt a 6-year curriculum with an additional year of internship where interns rotate in all dental specialties but not dental sleep medicine. The curriculum exposes dental students to some knowledge about OSA in the subjects of orthodontics and maxillofacial surgery. The interns were approached at the end of a curricular class and were invited to answer a 46-item questionnaire about the signs, symptoms, risk factors, and complications of OSA. They all agreed to answer the study questionnaire.

The authors created the study questionnaire based on a prior survey developed by Collison et al. which targeted knowledge of OSA among primary care physicians. ${ }^{9}$ Questions were added to cover dental and nondental-related OSA areas uncovered in the aforementioned version. In the adult signs and symptoms subscale, seven questions were added. The questions asked about dental/ oral-related signs and symptoms such as bruxism, dry mouth, and hyponasal speech. Other questions included morning headache after sufficient sleep and poor work performance as manifestations of OSA. A subscale about children signs and symptoms was added, with questions enquiring about sleeping position, ribcage movement during sleep, bedwetting, choking or drooling during sleep, and reduced school performance or behavioral disorders. In the OSA predisposing factors' subscale, questions about smoking, sleeping on the stomach, having a large neck circumference, having a high Mallampati score (intubation difficulty), and having a large tongue were added. No questions were added to the complications' subscale.

The final questionnaire contained four subscales: OSA signs and symptoms in adults ( 18 items), OSA signs and symptoms in children (5 items), OSA risk factors (11 items), and OSA complications (12 items). Each item consisted of a statement followed by a question whether the intern thought the statement was true, false, or was not sure. The study objectives and the overall structure of the study tool were explained to the interns before they self-filled the questionnaire. The proportions of correct, incorrect, and unsure responses were calculated.

\section{Results}

The participants' age range was 23 to 25 years. Tables 1 to 4 and Figure 1 demonstrate percentages of factually correct responses to the questions in the questionnaire. The average of the proportions of factually correct participant responses of the questionnaire categories was $47 \%$. The proportion of factually correct responses in the whole study sample exceeded $50 \%$ in only 14 of the 46 questions. Participants did best in the category of questions related to predisposing factors ( $50 \%$ of questions were answered correctly) but less than $50 \%$ of questions were answered correctly
Table 1: Percentages of correct, incorrect, and ambivalent responses to questionnaire statements about obstructive sleep apnea (OSA) symptoms in adults. The total number of responses was 158

\begin{tabular}{|c|c|c|c|c|}
\hline \multicolumn{2}{|c|}{ Statement } & \multirow{2}{*}{$\begin{array}{l}\text { Correct } \\
37\end{array}$} & \multirow{2}{*}{$\begin{array}{l}\text { Incorrect } \\
33\end{array}$} & \multirow{2}{*}{$\begin{array}{l}\text { Unsure } \\
30\end{array}$} \\
\hline 1 & All people with OSA snore & & & \\
\hline 2 & $\begin{array}{l}\text { People with OSA know there is } \\
\text { something wrong with them }\end{array}$ & 39 & 39 & 23 \\
\hline 3 & $\begin{array}{l}\text { People with OSA are often sleepy } \\
\text { during the day }\end{array}$ & 54 & 26 & 20 \\
\hline 4 & $\begin{array}{l}\text { Difficulty in waking up is not } \\
\text { related to OSA }\end{array}$ & 53 & 21 & 26 \\
\hline 5 & $\begin{array}{l}\text { Limb movements during sleep } \\
\text { are not related to OSA }\end{array}$ & 33 & 28 & 39 \\
\hline 6 & Bruxism is not related to OSA & 17 & 48 & 35 \\
\hline 7 & $\begin{array}{l}\text { Having a dry mouth or sore } \\
\text { throat upon waking up could } \\
\text { indicate OSA }\end{array}$ & 72 & 11 & 17 \\
\hline 8 & $\begin{array}{l}\text { People with OSA often have poor } \\
\text { memory }\end{array}$ & 35 & 31 & 34 \\
\hline 9 & Dentists cannot detect OSA & 74 & 9 & 16 \\
\hline 10 & $\begin{array}{l}\text { Poor work performance could be } \\
\text { a sign of OSA }\end{array}$ & 64 & 15 & 21 \\
\hline 11 & $\begin{array}{l}\text { Restless leg syndrome is not } \\
\text { related to OSA }\end{array}$ & 30 & 28 & 42 \\
\hline 12 & $\begin{array}{l}\text { Poor concentration is considered } \\
\text { a symptom of OSA }\end{array}$ & 62 & 16 & 22 \\
\hline 13 & $\begin{array}{l}\text { Sudden awakening with gasping } \\
\text { for air or choking is unrelated to } \\
\text { having OSA }\end{array}$ & 51 & 32 & 17 \\
\hline 14 & $\begin{array}{l}\text { The appearance of people with } \\
\text { OSA never indicates having the } \\
\text { condition }\end{array}$ & 44 & 28 & 28 \\
\hline 15 & Dentists can treat OSA & 48 & 31 & 21 \\
\hline 16 & $\begin{array}{l}\text { Hyponasal speech is considered } \\
\text { a sign of OSA }\end{array}$ & 58 & 13 & 29 \\
\hline 17 & $\begin{array}{l}\text { Diagnosis can be reached by } \\
\text { interviewing only the spouse of a } \\
\text { person with OSA }\end{array}$ & 43 & 26 & 31 \\
\hline 18 & $\begin{array}{l}\text { A morning headache after sleep- } \\
\text { ing for sufficient time is a sign } \\
\text { of OSA }\end{array}$ & 57 & 23 & 20 \\
\hline
\end{tabular}

in each of the other categories. Respondent scores (the number of questions they got right) were grouped into groups ascending by 10 percentile intervals starting from $49 \%$ (Fig. 2). The majority of participants scored $49 \%$ or lower. Cronbach's a was 0.75 , indicating acceptable internal consistency of the study tool.

\section{Discussion}

The routine dental visits and the accessibility of the upper airway give dentists a very advantageous position to screen their patients or OSA. ${ }^{10,11}$ However, suboptimal practitioner knowledge may well contribute to the underdiagnosis of OSA. The root of this knowledge deficit may be in the education these practitioners received in the undergraduate or postgraduate periods. The results showed that dental graduate scores were low on a questionnaire testing their knowledge related to signs, symptoms, predisposing factors, and consequences of OSA. For example, most participants did not know that that snoring is not always present in patients with OSA. 
Table 2: Frequencies and percentages of correct, incorrect, and ambivalent responses to questionnaire statements about obstructive sleep apnea (OSA) symptoms in children

\begin{tabular}{lllll}
\hline Signs and symptoms in children & Correct & Incorrect & Unsure \\
\hline 1 & $\begin{array}{l}\text { Bedwetting could be a sign of } \\
\text { sleep apnea }\end{array}$ & 37 & 26 & 37 \\
$2 \quad \begin{array}{l}\text { Choking or drooling during } \\
\text { sleeping is not related to OSA }\end{array}$ & 42 & 28 & 30 \\
$3 \quad \begin{array}{l}\text { Ribcage moves outward while } \\
\text { inhaling is a sign of OSA }\end{array}$ & 24 & 29 & 47 \\
$4 \quad \begin{array}{l}\text { Learning and behavioral } \\
\text { disorders and poor school } \\
\text { performance are not related to } \\
\text { OSA }\end{array}$ & 41 & 30 & 28 \\
$5 \quad \begin{array}{l}\text { Unusual or funny sleeping } \\
\text { positions could be a sign of OSA }\end{array}$ & 57 & 17 & 26 \\
\hline
\end{tabular}

Table 3: Frequencies and percentages of correct, incorrect, and ambivalent responses to questionnaire statements about predisposing factors and complications related to obstructive sleep apnea (OSA)

\begin{tabular}{|c|c|c|c|c|}
\hline \multicolumn{2}{|c|}{ Predisposing factors } & \multirow{2}{*}{$\frac{\text { Correct }}{44}$} & \multirow{2}{*}{$\frac{\text { Incorrect }}{27}$} & \multirow{2}{*}{$\begin{array}{l}\text { Unsure } \\
29\end{array}$} \\
\hline 1 & $\begin{array}{l}\text { OSA is predominantly an illness } \\
\text { of females }\end{array}$ & & & \\
\hline 2 & $\begin{array}{l}\text { OSA is predominantly an illness } \\
\text { of the young }\end{array}$ & 46 & 23 & 32 \\
\hline 3 & $\begin{array}{l}\text { Alcohol, muscle relaxants, and } \\
\text { sleeping pills help you relax and } \\
\text { therefore help reduce OSA }\end{array}$ & 40 & 35 & 25 \\
\hline 4 & $\begin{array}{l}\text { A large tongue is a risk factor for } \\
\text { OSA }\end{array}$ & 73 & 13 & 13 \\
\hline 5 & $\begin{array}{l}\text { A high Mallampati score (intuba- } \\
\text { tion difficulty) is not related to } \\
\text { OSA }\end{array}$ & 45 & 24 & 31 \\
\hline 6 & $\begin{array}{l}\text { A big neck circumference in- } \\
\text { creases the risk of having OSA }\end{array}$ & 61 & 14 & 25 \\
\hline 7 & $\begin{array}{l}\text { Narrowed airway does not in- } \\
\text { crease the risk of developing OSA }\end{array}$ & 63 & 23 & 15 \\
\hline 8 & $\begin{array}{l}\text { Sleeping on the stomach in- } \\
\text { creases the risk of OSA }\end{array}$ & 32 & 29 & 39 \\
\hline 9 & Smoking is not related to OSA & 47 & 20 & 33 \\
\hline 10 & Being anorexic is a risk factor & 27 & 32 & 41 \\
\hline 11 & Obesity is related to OSA & 68 & 12 & 20 \\
\hline
\end{tabular}

A majority did not know that OSA affects memory or contribute to bruxism. Most of these graduates were not aware that dentists can help with treating OSA. In a country with an epidemic of diabetes, obesity, and vascular risk factors, most dental graduates were unaware that OSA can elevate blood pressure and lead to cardiac complications. This lack of knowledge may lead to a huge loss of opportunity to improve important public health problems and integrate dentists into the healthcare system.

Our results are comparable to the results of a prior study that examined the responses of Saudi final year dental students and showed that more than two thirds of a sample of dental students were unaware of how OSA is diagnosed. ${ }^{8}$ This is also consistent with various reports that OSA knowledge is not optimal among general dentists. ${ }^{712-14}$ This knowledge gap is not surprising, given the fact that OSA does not appear to be sufficiently covered during undergraduate dental education and general dentists often reported not being exposed sufficiently to educational experiences that would
Table 4: Frequencies and percentages of correct, incorrect, and ambivalent responses to questionnaire statements about complications related to obstructive sleep apnea (OSA)

\begin{tabular}{|c|c|c|c|c|}
\hline \multicolumn{2}{|c|}{ Complications } & \multirow{2}{*}{$\begin{array}{l}\text { Correct } \\
42\end{array}$} & \multirow{2}{*}{$\begin{array}{l}\text { Incorrect } \\
29\end{array}$} & \multirow{2}{*}{$\begin{array}{l}\text { Unsure } \\
29\end{array}$} \\
\hline 1 & $\begin{array}{l}\text { OSA is not related to } \\
\text { hypertension }\end{array}$ & & & \\
\hline 2 & $\begin{array}{l}\text { OSA can lead to a shorter life } \\
\text { expectancy }\end{array}$ & 63 & 16 & 16 \\
\hline 3 & OSA can be controlled with drugs & 41 & 27 & 27 \\
\hline 4 & OSA can be treated by surgery & 62 & 22 & 22 \\
\hline 5 & $\begin{array}{l}\text { Depression is not a complication } \\
\text { of OSA }\end{array}$ & 52 & 23 & 23 \\
\hline 6 & Epilepsy is not related to OSA & 27 & 32 & 32 \\
\hline 7 & $\begin{array}{l}\text { The risk of stroke is increased in } \\
\text { patients with OSA }\end{array}$ & 50 & 22 & 22 \\
\hline 8 & $\begin{array}{l}\text { People with OSA are OK driving } \\
\text { motor vehicles }\end{array}$ & 47 & 27 & 27 \\
\hline 9 & $\begin{array}{l}\text { Managing type } 2 \text { diabetes is not } \\
\text { affected by having OSA }\end{array}$ & 34 & 27 & 27 \\
\hline 10 & $\begin{array}{l}\text { All the effects of OSA are } \\
\text { reversed after treatment }\end{array}$ & 26 & 35 & 35 \\
\hline 11 & OSA can reduce the IQ & 46 & 24 & 24 \\
\hline 12 & $\begin{array}{l}\text { OSA may lead to cardiac } \\
\text { complications }\end{array}$ & 44 & 18 & 18 \\
\hline
\end{tabular}

enable them to gain knowledge and awareness regarding OSA. ${ }^{7}$ This potential deficit in undergraduate dental curricula was studied specifically in the Middle East, showing that dental students may be receiving a mere 1.2 hours of teaching about sleep medicine, ${ }^{15}$ which is arguably insufficient to teach dental students about how to aid in the detection and referral of a major public health problem they are particularly positioned to contribute. Of note, the average number of hours devoted to sleep-related topics in dental curricula in a sample of US dental schools was nearly 4 hours. ${ }^{11}$

A plea was made in 2012 by Ivanoff et al. to prepare dental graduates to detect patients at risk of OSA and to be well equipped to educate the public about OSA risk factors and prevention. ${ }^{16}$ This plea originated from the seriousness of medical consequences of OSA, the high prevalence, and the expected increase in the prevalence of OSA. The same plea has to be made in Saudi Arabia where obesity, the number one risk factor for OSA, is an epidemic. ${ }^{17,18}$ Improving dental practitioners' OSA knowledge is of paramount importance. This could be achieved through updating dental school curricula to include didactic and clinical teaching of OSA, in addition to incorporating OSA screening questionnaires in the history-taking routine. The ultimate goal is for dentists to be competent in screening for OSA and refereeing patients at risk. It is also of paramount importance to have enough dentists who are competent in treating OSA with OAT following the standards of care. This could be achieved through developing local programs by certified sleep dentists to training dentists in OSA treatment with OAT. One of the obstacles that would make it difficult to reach these goals is the limited number of certified sleep dentists. This can be overcome by intensive workshops for general dentists and dentists from other specialties, so that knowledge is disseminated through a larger network of professionals.

This study has limitations. Dental interns are not necessarily representative of the population of general or subspecialized dentists. The sample is not necessarily representative of dental interns from all regions of Saudi Arabia or the Middle East. Selection 


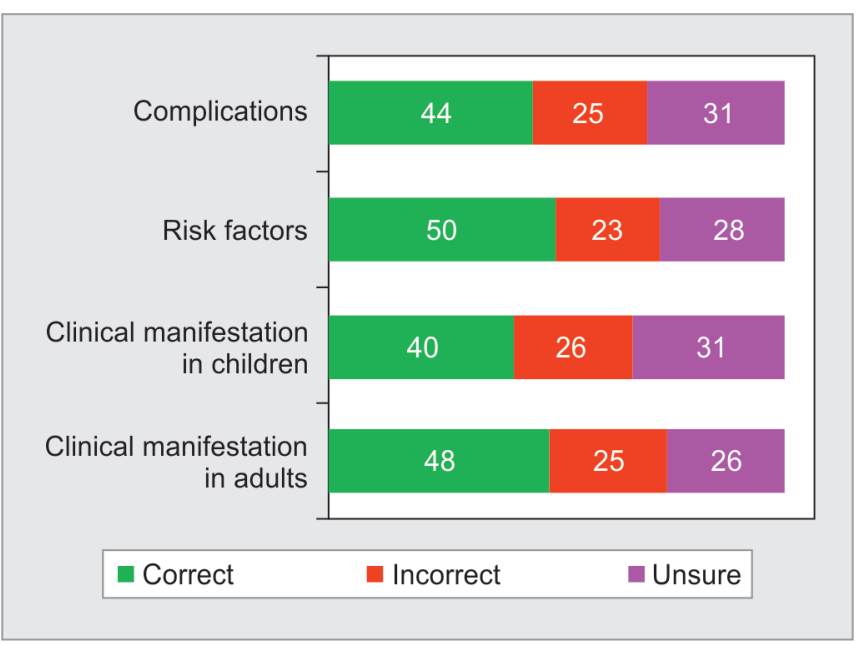

Fig. 1: Stacked bar graph demonstrating the percentages of correct, incorrect, and unsure response to each of the questionnaire subscales

bias cannot be ruled out, given the fact that this was a convenient sample of interns in training who were attending a curricular lecture, which may mean that they are less or more knowledgeable than the average graduate. Finally, the study questionnaire was based on previously utilized tools to assess awareness, but the validity of the tool in this context has not been established. An additional study with a larger sample that validates the questionnaire and selects a wider spectrum of practitioners as a sample is needed to address the above limitations.

\section{Conclusion}

In conclusion, our data revealed that dental graduates are not very well informed about OSA. This may raise the possibility that undergraduate dental education does not prepare dentists well to help in detecting patients at risk of OSA and referring them to the sleep clinic. Remedying this gap in knowledge and skills may help mitigate the negative effects of OSA. Future studies are needed to investigate how this may be attained efficiently in dental curricula.

\section{Acknowledgment}

The authors would like to acknowledge Dr Hussam Alghamdi and Dr Battar Alghamdi for their participation in the data collection.

\section{References}

1. Park JG, Ramar K, Olson EJ. Updates on definition, consequences, and management of obstructive sleep apnea. Mayo Clin Proc 2011;86(6):549-555. DOI: 10.4065/mcp.2010.0810.

2. Redline S. Screening for obstructive sleep apnea: implications for the sleep health of the population. J Am Med Assoc 2017;317(4):368-370. DOI: 10.1001/jama.2016.18630.

3. Wali SO, Abalkhail B, Krayem A. Prevalence and risk factors of obstructive sleep apnea syndrome in a Saudi Arabian population. Ann Thorac Med 2017;12(2):88-94. DOI: 10.4103/1817-1737.203746.

4. Quan SF, Schmidt-Nowara W. The role of dentists in the diagnosis and treatment of obstructive sleep apnea: consensus and controversy. J Clin Sleep Med 2017;13(10):1117-1119. DOI: 10.5664/jcsm.6748.

5. Levendowski DJ, Morgan T, Montague J, et al. Prevalence of probable obstructive sleep apnea risk and severity in a population of dental patients. Sleep Breath 2008;12(4):303-309. DOI: 10.1007/s11325-0080180-z.

6. Ramar K, Dort LC, Katz SG, et al. Clinical practice guideline for the treatment of obstructive sleep apnea and snoring with oral appliance

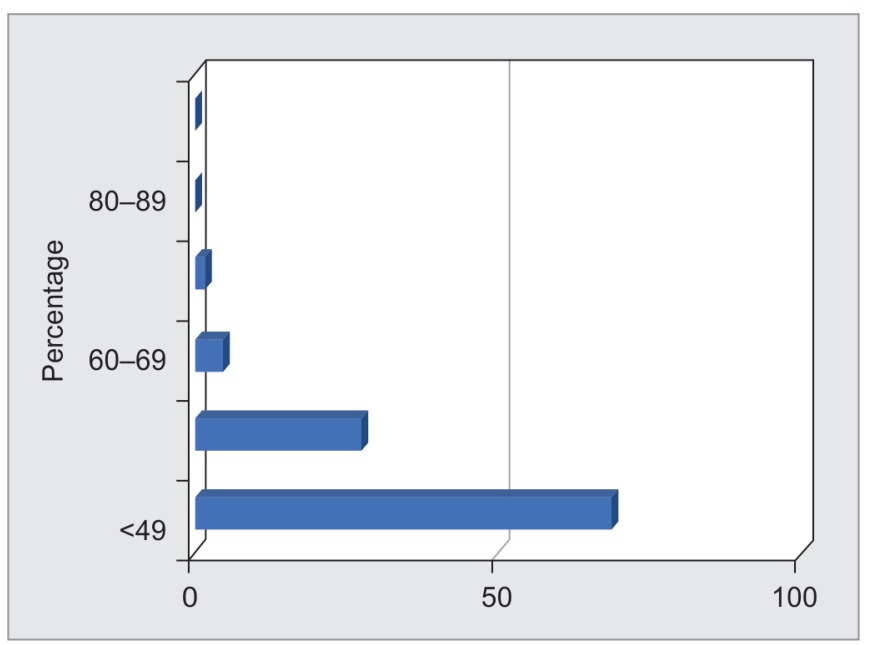

Fig. 2: A bar graph demonstrating the number of students achieving total scores for each of the percentile ranges

therapy: an update for 2015. J Clin Sleep Med 2015;11(7):773-827. DOI: 10.5664/jcsm.4858.

7. Bian $\mathrm{H}$. Knowledge, opinions, and clinical experience of general practice dentists toward obstructive sleep apnea and oral appliances. Sleep Breath 2004;8(2):85-90. DOI: 10.1007/s11325-004-0085-4.

8. Amara Swapna L, Alotaibi NF, Falatah SA, et al. Knowledge of obstructive sleep apnea among dental fraternity in Riyadh. Open Access Maced J Med Sci 2019;7(15):2508-2512. DOI: 10.3889/oamjms.2019.654.

9. Collison MO, Man GCW, Kang BV. Level of awareness of sleep apnea among Alberta's physicians: a survey. Sleep Res 1995;24:214.

10. Manski RJ, Moeller JF, Maas WR. Dental services. an analysis of utilization over 20 years. J Am Dent Assoc 2001;132(5):655-664. DOI: 10.14219/jada.archive.2001.0243.

11. Simmons MS, Pullinger A. Education in sleep disorders in US dental schools DDS programs. Sleep Breath 2012;16(2):383-392. DOI: 10.1007/s11325-011-0507-z.

12. Jokubauskas L, Pileičikienè G, Žekonis G, et al. Lithuanian dentists' knowledge, attitudes, and clinical practices regarding obstructive sleep apnea: a nationwide cross-sectional study. Cranio 2019;37(4):238-245. DOI: 10.1080/08869634.2018.1437006.

13. Meenakshi RS, Kumar KS, Prabhakar K. Evaluation of awareness of issues regarding obstructive sleep apnea and the orthodontist role in management: a survey among dental and medical practitioners. $J$ Indian Acad Dent Special Res, https://link.galegroup.com/apps/ doc/A496539733/AONE?sid=Ims. Published July 1, 2016. Accessed January 1, 2020.

14. Jauhar S, Lyons MF, Banham SW, et al. The attitudes of general dental practitioners and medical specialists to the provision of intra-oral appliances for the management of snoring and sleep apnoea. Br Dent J 2008;205(12):653-657. DOI: 10.1038/sj.bdj.2008. 1022.

15. Talaat W, AlRozzi B, Kawas SA. Sleep medicine education and knowledge among undergraduate dental students in middle east universities. Cranio 2016;34(3):163-168. DOI: 10.1179/2151090315Y.0000000019.

16. Ivanoff CS, Hottel TL, Pancratz F. Is there a place for teaching obstructive sleep apnea and snoring in the predoctoral dental curriculum? J Dent Educ 2012;76(12):1639-1645.

17. Ng SW, Zaghloul S, Ali HI, et al. The prevalence and trends of overweight, obesity and nutrition-related non-communicable diseases in the arabian gulf states. Obes Rev 2011;12(1):1-13. DOI: 10.1111/j.1467-789X.2010.00750.x.

18. Al-Hazzaa HM, Abahussain NA, Al-Sobayel HI, et al. Prevalence of overweight, obesity, and abdominal obesity among urban saudi adolescents: gender and regional variations. J Health Popul Nutr 2014;32(4):634-645. 